\title{
'Juntando a fome com a vontade de comer': discussão sobre implementação de infraestrutura cicloviária como forma de promover inclusão social e sustentabilidade em Prado, Bahia, Brasil
}

'Juntando a fome com a vontade de comer': discussion on the implementation of cycle infrastructure as a way to promote social equity and sustainability in Prado, Bahia, Brazil

"Juntando el hambre con la voluntad de comer": discusión sobre implementación de infraestructura cicloviaria como forma de promover inclusión social y sostenibilidad en Prado, Bahía, Brasil

\author{
Ana Mesquita-Emlinger ${ }^{1}$ \\ Salem State University, EUA \\ Rita de Cássia-Bruno ${ }^{2}$ \\ Universidade Católica Dom Bosco, Brasil
}

1 Doutor em Planejamento Urbano Regional pela University of Massachusetts Amherst. Professor Assistente no Departmento de Geografia da Salem State University, EUA. E-mail: aemlinger@salemstate.edu

2 Especialista em Auditoria e Perícia Contábil pela Universidade Católica Dom Bosco, Campo Grande, MS. Assistante de Pesquisa, Prado, Brazil. E-mail: ritadecassiabruno@terra.com.br 
Ana Mesquita-Emlinger, Rita de Cássia-Bruno. 'Juntando a fome com a vontade de comer': discussion on the implementation of cycle infrastructure as a way to promote social equity and sustainability in

Prado, Bahia, Brazil

\title{
Resumo
}

O ciclismo na mobilidade urbana é um hábito benéfico de transporte ativo. Pesquisas afirmam que o ciclismo urbano está associado não apenas à disponibilidade de infraestrutura cicloviária, topografia favorável, forma urbana e clima ameno, mas principalmente ao hábito de pedalar. Em Prado, uma pequena cidade histórica e turística do Nordeste brasileiro, a bicicleta é utilizada pelos moradores como um dos principais meios de transporte, apesar da absoluta falta de infraestrutura cicloviária na cidade. Este artigo enfoca as possibilidades de implementação de uma rede cicloviaria nesta localidade. Uma pesquisa com moradores locais foi realizada para entender o perfil dos ciclistas, os padrões e a frequência das viagens, bem como os problemas específicos enfrentados pelos ciclistas na cidade. Este artigo discute os resultados preliminares desta pesquisa. Tanto ciclistas quanto não-ciclistas concordam que a implementação da infraestrutura cicloviária serviria não apenas como um motivador para incorporar a bicicleta como meio de transporte diário, mas também impactaria no aumento da frequência daqueles que ocasionalmente a utilizam. Uma rede de ciclovias em Prado poderá beneficiar o residente comum durante todo o ano, assim como os turistas que visitam a cidade. Essa abordagem, ao divergir da tradição de melhorias urbanas, muitas vezes voltadas para as áreas centrais e elitizadas das cidades americanas e brasileiras, torna-se um bom exemplo de equidade social e sustentabilidade.

Palavras-chave: Infraestrutura Cicloviária; Cidade; Sustentabilidade; Inclusão Social.

\begin{abstract}
Cycling in urban mobility is a beneficial habit of active transport. Researches affirm that urban cycling is associated not only with the availability of cycle infrastructure, favorable topography, urban form and mild climate, but mainly to the habit of pedaling. In Prado, a small historical and tourist city in northeastern Brazil, the bicycle is used by residents as one of the main means of transportation, despite the absolute lack of cycling infrastructure in the city. This article focuses on the possibilities of implementing a cycle network in this locality. A survey of local residents was conducted to understand cyclists' profile, patterns and travel frequency, as well as specific problems faced by cyclists in the city. This article discusses the preliminary results of this research. Both cyclists and non-cyclists who participated in the research agree that the implementation of cycling infrastructure would serve not only as a motivator for incorporating the bicycle as a means of daily transportation, but would impact the increase of frequency for those who occasionally use it. A cycle network in Prado would benefit the common resident throughout the year as well as tourists visiting the city. This approach, by diverging from the tradition of urban improvements often aimed at the central areas of American and Brazilian cities, becomes a good example of social equity, and sustainability.
\end{abstract}

Keywords: Bicycling infrastructure; City; Sustainability; Social Inclusion.

\section{Resumen}

El ciclismo en la movilidad urbana es un hábito benéfico de transporte activo. Las investigaciones afirman que el ciclismo urbano está asociado no sólo a la disponibilidad de infraestructura cicloviaria, topografía favorable, forma urbana y clima templado, pero principalmente al hábito de pedalear. En Prado, una pequeña ciudad histórica y turística del Nordeste brasileño, la bicicleta es utilizada por los residentes como uno de los principales medios de transporte, a pesar de la absoluta falta de infraestructura cicloviaria en la ciudad. Este artículo enfoca las posibilidades de implementación de una red cicloviaria en esta localidad. Una encuesta con residentes locales se realizó para entender el perfil de los ciclistas, los patrones y la frecuencia de los viajes, así como los problemas específicos que enfrentan los ciclistas en la ciudad. Este artículo discute los resultados preliminares de esta

434 Revista Geográfica de América Central No 61E (3) Especial CLAG Este artículo está bajo una licencia e-ISSN 2215-2563 • Julio-diciembre 2018 • pp. 433-451 Doi: http://dx.doi.org/10.15359/rgac.61-3.22

CompartirIgual 4.0 Internacional 
Ana Mesquita-Emlinger, Rita de Cássia-Bruno. 'Juntando a fome com a vontade de comer': discussão sobre implementação de infraestrutura cicloviária como forma de promover inclusão social e sustentabilidade em Prado, Bahia, Brasil

investigación. Tanto los ciclistas como los no ciclistas están de acuerdo en que la implementación de la infraestructura cicloviária no sólo serviría de motivación para incorporar la bicicleta como medio de transporte diario, pero también afectaría al aumento de la frecuencia de los que ocasionalmente la utilizan. Una red de ciclovías en Prado beneficiaría al residente común durante todo el año, así como a los turistas que visitan la ciudad. Este enfoque, al divergir de la tradición de mejoras urbanas, muchas veces dirigidas a las áreas centrales y elitizadas de las ciudades americanas y brasileñas, se convierte en un buen ejemplo de equidad social y sostenibilidad.

Palabras clave: Infraestructura Cicloviária; Ciudad; Sostenibilidad; Equidad Social; Justicia

\section{Introdução}

Esta pesquisa está primariamente interessada em estudar a cidade de Prado, Bahia, Brasil, especialmente sob a ótica do uso de bicicleta na mobilidade urbana e as suas relações no campo de sustentabilidade e equidade social. Tem como principal objetivo discutir a oportunidade de futura implantação de infraestrutura cicloviária na cidade. Atualmente, apesar do grande número de moradores pradenses usarem a bicicleta como seu principal meio de transporte, não há nenhum tipo de infraestrutura urbana dedicada a este fim. Daí utilizarmos a expressão popular "juntar a fome com a vontade de comer", como forma de expressar a idéia de unir interesses e aproveitar duas oportunidades que se apresentam ao mesmo tempo em uma determinada situação. No caso de Prado, a união do hábito e/ou necessidade de pedalar com a imprescindibilidade de uma infraestrutura segura de suporte ao ciclismo.

O uso de formas alternativas de transporte está entre as grandes preocupações da vida moderna. Muitas cidades ao redor do mundo têm investido esforços consideráveis para que seus moradores incorporem a caminhada e/ou a bicicleta em seu cotidiano. Em Prado, felizmente, este hábito já faz parte do dia-a-dia de muitos residentes (Figura 1). 
Figura 1. Bicicleta faz parte do cotidiano da população em Prado, Bahia.

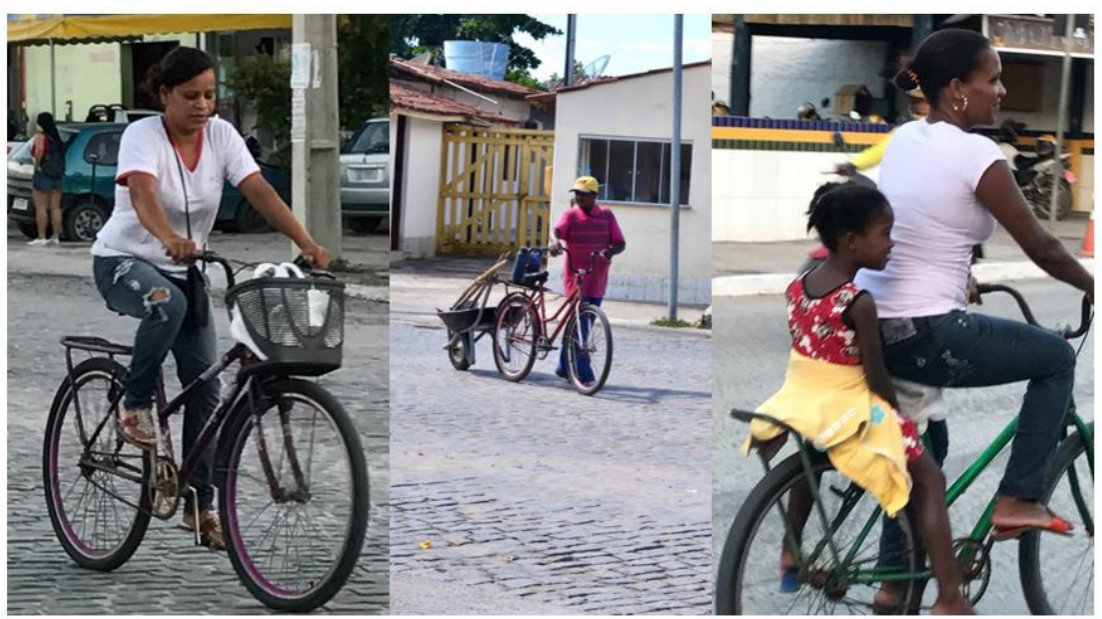

Fonte: Fotos de Rita de Cássia Bruno.

No entanto, muitos deles envergonham-se disto, por carregarem um estigma do empobrecimento fortemente ligado ao uso de bicicleta como meio de transporte. Um olhar histórico neste contexto faz-se importante na tentativa de compreender as razões pelas quais o uso de bicicleta tem, para muitas pessoas na cidade (e no país), uma carga socioeconômica pejorativa. Vindas da Europa, as bicicletas chegaram ao Brasil na segunda metade do século XIX, como meio de transporte destinado a uma classe social trabalhadora e empobrecida, que não tinha condições econômicas de possuir um veículo automotor. Este estigma parece acompanhar o povo brasileiro desde então, reforçado por uma política urbana equivocada, que não valorizou o pedestre e/ou o ciclista como deveria e que ainda patina para encontrar soluções de transporte menos agressivas ao meio ambiente.

Em 2002, a terceira conferência da ONU estabeleceu a Agenda 21, enfatizando as cidades sustentáveis e a redução das desigualdades sociais. Felizmente o país reconheceu o crescimento das cidades e as dificuldades em relação a mobilidade urbana. Em 2003, como relembra Soares (2015), foi criado o Ministério das Cidades, visando democratizar o acesso aos beneficíos da vida urbana, e adotando a mobilidade com segurança como fator de inclusão social. 
Ana Mesquita-Emlinger, Rita de Cássia-Bruno. 'Juntando a fome com a vontade de comer': discussão sobre implementação de infraestrutura cicloviária como forma de promover inclusão social e sustentabilidade em Prado, Bahia, Brasil

Iniciativas de valorização da bicicleta como meio de transporte têm despontado em todo o país. A Revista Exame publicou em 2014 um levantamento da ONG Mobilize Brasil, reunindo informações sobre a soma das malhas cicloviárias das 12 capitais que possuem vias exlclusivas para bicicletas. $\mathrm{O}$ quadro a seguir (Tabela 1) mostra esses dados de forma sumária, destacando a extenção das ciclovias nas capitais e a relação dessas pistas com a malha viária total, a qual serve aos transportes motorizados e mais poluentes.

Tabela 1. Doze capitais brasileiras com mais extensão de ciclovias em Km

\begin{tabular}{|c|c|c|c|c|}
\hline $\begin{array}{c}\text { Capital } \\
\text { Brasileira }\end{array}$ & $\begin{array}{l}\text { Extensão de } \\
\text { Ciclovias }\end{array}$ & $\begin{array}{l}\text { Sistema } \\
\text { Viário }\end{array}$ & $\begin{array}{c}\text { Relação à } \\
\text { Extensão do } \\
\text { Sistema Viário }\end{array}$ & $\begin{array}{c}\text { Emissoes } \\
\text { do Setor de } \\
\text { Transporte }\end{array}$ \\
\hline Rio de Janeiro & $300 \mathrm{~km}$ & $9464 \mathrm{~km}$ & $3,17 \%$ & $\begin{array}{c}4.574 .864 \text { ton/ano } \\
\text { de C02 eq. }\end{array}$ \\
\hline Brasília & $160 \mathrm{~km}$ & $10.500 \mathrm{~km}$ & $1,52 \%$ & $\begin{array}{c}3.190 .676 \text { ton/ano } \\
\text { de C02 eq. }\end{array}$ \\
\hline Curitiba & $127 \mathrm{~km}$ & $4700 \mathrm{~km}$ & $2,7 \%$ & $\begin{array}{c}2.578 .404 \text { ton/ano } \\
\text { de } \mathrm{C} 02 \mathrm{eq} .\end{array}$ \\
\hline Campo Grande & $79 \mathrm{~km}$ & $3.966 \mathrm{~km}$ & $1,99 \%$ & $\mathrm{~N} / \mathrm{C}$ \\
\hline São Paulo & $69.8 \mathrm{~km}$ & $18.000 \mathrm{~km}$ & $0,39 \%$ & $\begin{array}{l}\text { 12.605.199 ton/ } \\
\text { ano de C02 eq. }\end{array}$ \\
\hline Fortaleza & $70 \mathrm{~km}$ & $3.887 \mathrm{~km}$ & $1,81 \%$ & $\begin{array}{c}1.273 .178 \text { ton/ano } \\
\text { de C02 eq. }\end{array}$ \\
\hline Aracaju & $55 \mathrm{Km}$ & $\mathrm{N} / \mathrm{C}$ & $\mathrm{N} / \mathrm{C}$ & $\mathrm{N} / \mathrm{C}$ \\
\hline Recife & $28,5 \mathrm{Km}$ & $\mathrm{N} / \mathrm{C}$ & $\mathrm{N} / \mathrm{C}$ & $\begin{array}{l}985.143 \text { ton/ano } \\
\text { de C02 eq. }\end{array}$ \\
\hline Florianópolis & $37 \mathrm{~km}$ & $1.809 \mathrm{~km}$ & $2,02 \%$ & $\mathrm{~N} / \mathrm{C}$ \\
\hline Salvador & $19 \mathrm{~km}$ & $5.000 \mathrm{~km}$ & $0,38 \%$ & $\begin{array}{c}1.967 .923 \text { ton/ano } \\
\text { de C02 eq. }\end{array}$ \\
\hline Cuiabá & $15 \mathrm{Km}$ & $1789 \mathrm{~km}$ & $0,81 \%$ & $\begin{array}{c}1.029 .815 \text { tom'ano } \\
\text { de C02 eq. }\end{array}$ \\
\hline Porto Alegre & $12 \mathrm{~km}$ & $2733 \mathrm{~km}$ & $0,44 \%$ & $\begin{array}{c}1.858 .990 \text { ton/ano } \\
\text { de C02 eq. }\end{array}$ \\
\hline
\end{tabular}

Fonte: Tabela organizada pelas autoras com dados publicados por Vanessa Barbosa na Revista Exame (2016).

Muitos são os fatores que asseguram cidades européias serem lideres em políticas cicloviárias implementadas. Como refletem Pucher, Komanoff, and Schimek (1999), cidades na Alemanha, Dinamarca e Holanda 
Ana Mesquita-Emlinger, Rita de Cássia-Bruno. 'Juntando a fome com a vontade de comer': discussion on the implementation of cycle infrastructure as a way to promote social equity and sustainability in

priorizam ciclistas em algumas ruas, intersecções e rotineiramente empregam sinais verdes de trânsito adiantados e ruas munidas de soluções de "traffic-calming". Algumas cidades européias têm espaço de estacionamento dedicado para ciclovias ou estacionamento de bicicletas, para permitir o ciclismo e desestimular o uso de automóveis.

A implementação de ciclovias na cidade certamente aumentará esta demanda e motivará novos adeptos. Os resultados da pesquisa "Perfil de quem usa bicicleta na cidade de São Paulo", publicada durante a Semana da Mobilidade 2015, revelaram que 40\% dos ciclistas começaram a pedalar há menos de um ano nas áreas central e intermediária da cidade, possivelmente influenciados pela expansão da malha cicloviária (Caldeira, 2015).

Em 2050, 70\% das pessoas do mundo viverão em cidade e assentamentos urbanos (ONU-Habitat). Walker (2014) argumenta que, de longe, o maior número de novas moradias urbanas estarão em cidades novas e em expansão no mundo em desenvolvimento, e não nas antigas cidades do mundo desenvolvido. A região de Prado já demonstra desgaste ambiental devido a escolhas equivocadas do passado. Um dos mais evidentes ocorreu devido a grande tempestade de 2013 que destruiu parte do La Isla Ecoresort (Figura 2).

Figura 2. Destruição parcial do La Isla Ecoresort em 2013.

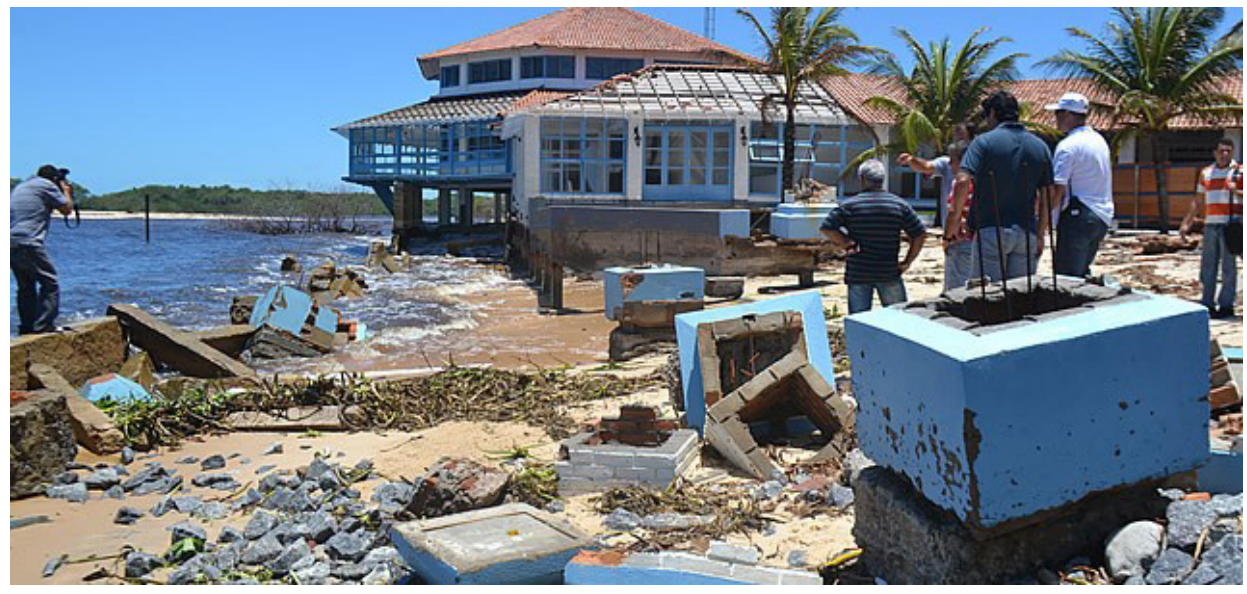

Fonte: G7 Notícias, disponível em http://g7noticias.com.br/prado-vereadores-lamentam-o-problema-que-o-resort-la-isla-enfrenta/ 
Ana Mesquita-Emlinger, Rita de Cássia-Bruno. 'Juntando a fome com a vontade de comer': discussão sobre implementação de infraestrutura cicloviária como forma de promover inclusão social e sustentabilidade em Prado, Bahia, Brasil

Houve uma ruptura significativa na linha de costa e o Rio Jucuruçu passou a ter uma abertura para o mar que atualmente comporta embarcações de medio porte, nunca antes vista neste local (Figura 3).

Figura 3. Rio Jucuruçu e ruptura da linha da costa na sua foz.

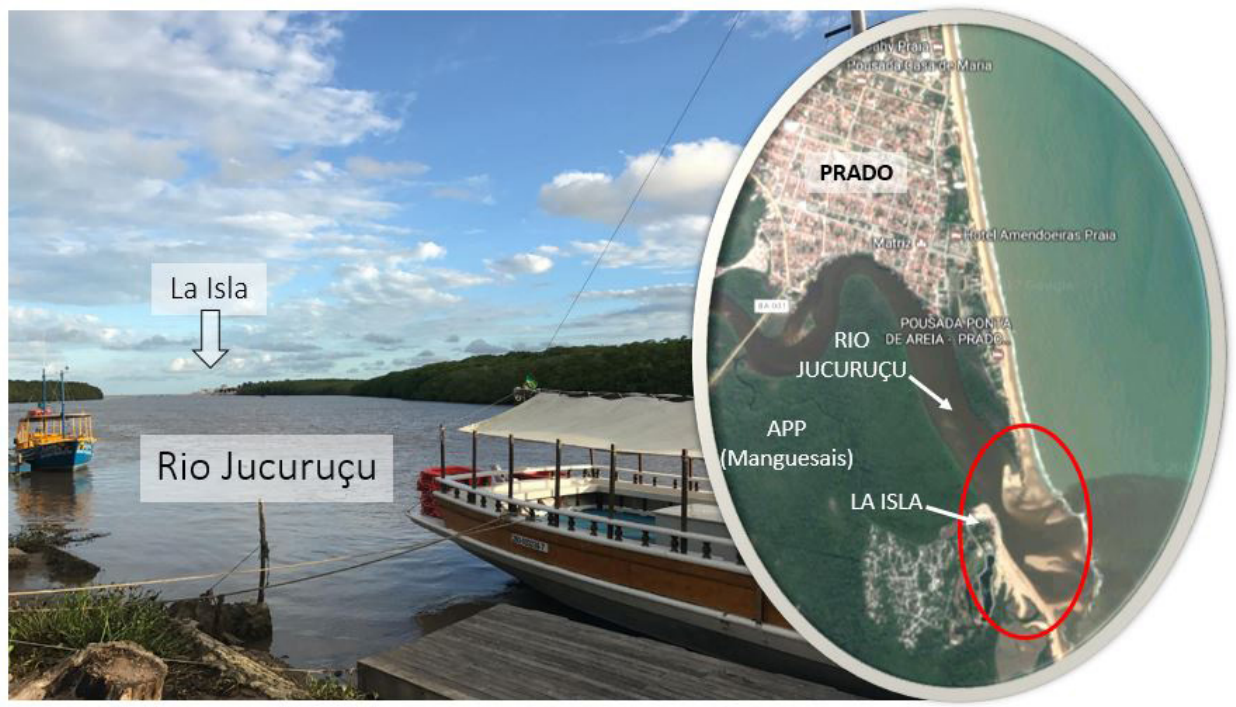

Fonte: Foto de Rita de Cássia Bruno / Foto aérea GOOGLE, adaptado pelas autoras.

O resort foi construído em área de mangue, deixando descoberto e desprotegido o solo que acabou por não resitir a grande tormenta, perdendo boa parte da frente e quase todas as barracas de praia foram destruídas. Curiosamente, em 2012, a então presidente do Brasil Dilma Roussef instituiu as APP - Áreas de Proteção Ambiental, protegendo todas as áreas de mangue do país. Manguezais reminiscentes em Prado passaram então a ser preservados.

Com este estudo busca-se aventar a possibilidade de Prado começar uma trajetória que objetive a resiliência, entendendo que cidades resilientes e sustentáveis são aquelas que podem reduzir seriamente seu impacto ambiental enquanto aumentam a sua capacidade econômica e de subsistência. 
Ana Mesquita-Emlinger, Rita de Cássia-Bruno. 'Juntando a fome com a vontade de comer': discussion on the implementation of cycle infrastructure as a way to promote social equity and sustainability in

Prado, Bahia, Brazil

\section{Benefícios da Mobilidade Sustentável}

As cidades precisam de um sistema de transporte sustentável que integre novas tecnologias e estratégias para fornecer um serviço de transporte eficiente e eficaz, reduzindo a emissão de GEE (Gases de Efeito Estufa) e melhorando sua habitabilidade, como pondera Huang (2015).

A gestão da mobilidade sustentável é sobre 'ruas e não estradas', as ruas são usadas para uma multiplicidade de propósitos, não apenas para maximizar o fluxo de veículos. A ênfase aqui está em alcançar a eficiência maximizando o movimento de pessoas, e alcançando um alto nível de comodidade e segurança para todos os usuários de rua, não somente para os veículos automotores.

Apesar de tantas vantagens, o ciclismo continua sendo um fator marginal em grande parte das políticas de transporte e saúde. De acordo com Winters, Davidson, Kao, \& Teschke (2011), as razões para isso podem ser, em parte, os riscos percebidos de colisões e exposição à poluição do ar associados ao ciclismo urbano, várias barreiras socio-psicológicas e ambientais, ou uma simples falta de priorização em políticas de planejamento urbano.

Neste contexto, parece-nos fundamental comecar uma conversa visando, como objetivo final, a implantação de uma rede de infraestrutura para bicicletas na cidade de Prado, criando opções de transporte seguras, de baixo custo, acessíveis e sustentáveis para pessoas de todas as idades e habilidades.

Pesquisas tem sido consistentes em revelar que o estacionamento de bicicletas na rua é mais do que um espaço para estacionar bicicletas. Também ajuda a reforçar uma cena de calçada vibrante que é boa para os pedestres. Bares e restaurantes em Prado certamente se beneficiariam com uma nova infraestrutura, que tem a capacidade de fornecer uma proteção contra o tráfego em movimento, valorizando lugares ao ar livre para cafés nas calçadas e canteiros centrais. Particularmente, para as pequenas empresas em Prado, obter uma melhor compreensão das escolhas e gastos dos consumidores é essencial não apenas para sua sobrevivência, mas também para seu crescimento.

\section{Urbanização Inclusiva e Equidade Social}

Especialistas em ciclismo concordam que construir redes cicloviárias é essencial. Mas eles também concordam que isso não é suficiente. Depois de um século construindo cidades ao redor de carros, as pessoas 
Ana Mesquita-Emlinger, Rita de Cássia-Bruno. 'Juntando a fome com a vontade de comer': discussão sobre implementação de infraestrutura cicloviária como forma de promover inclusão social e sustentabilidade em Prado, Bahia, Brasil

precisam estar expostas à ideia de que as bicicletas também podem ser uma maneira prática e agradável de se locomover. O desafio não é apenas colocar ciclovias, mas ajudar a transformar as paisagens locais, ligando as bicicletas com iniciativas comunitárias e programas que suportam bairros mais vibrantes e sustentáveis.

Maior, mais turbulenta e densamente povoada cidade da América, Nova Iorque mostra o importante papel que as bicicletas podem desempenhar na vida urbana do século XXI. O número de pessoas andando de bicicleta diariamente aumentou $80 \%$ de 2010 a 2015 - o período em que grandes melhorias cicloviárias começaram a aparecer nas ruas. O ciclismo, conforme afirma Goodyear (2015), tem continuamente crescido mais rápido do que qualquer outro meio de transporte em Nova Iorque, ao ponto que a cidade possui atualmente $675,9 \mathrm{Km}$ (420 milhas) de ciclovias intensamente utilizadas pelos residentes e turistas.

À medida que o mundo se urbaniza rapidamente e as mudanças climáticas cada vez mais impactam as pessoas, é de suma importância entender como planejar cidades que atendem a todos os cidadãos. Neste contexto, como incluir e representar todas as pessoas nas cidades? Um dos desafios é descobrir como a política e a gestão da urbanização podem ser usadas para criar cidades mais inclusivas e resilientes ao clima, buscando um modelo de vida e processos urbanos que levem em conta dimensões sociais, espaciais, culturais, regulatórias e econômicas. O foco, como afirmam Shrestha, Ojha, McManus, Rubbo e Dhote (2015), é encontrar uma maneira de tornar os processos e resultados do design urbano representativos de todos os habitantes da cidade.

As escolhas conscientes de hoje nos moverão em direção a um futuro mais sustentável, onde a política de infraestrutura urbana ajude as pessoas a desenvolverem hábitos diários mais saudáveis, e os padrões adotados largamente em todos os cantos do planeta tornarão a vida ecologicamente responsável e justa ainda mais difundida, refletem Scott, Amel, Koger, e Manning (2016).

\section{Localização Geográfica e Informações Socioeconômicas}

O município de Prado possui 27.627 habitantes (Censo 2010) e está localizado na região costeira do Estado da Bahia, Brasil (Figura 4). 
Figura 4. Localização geográfica de Prado

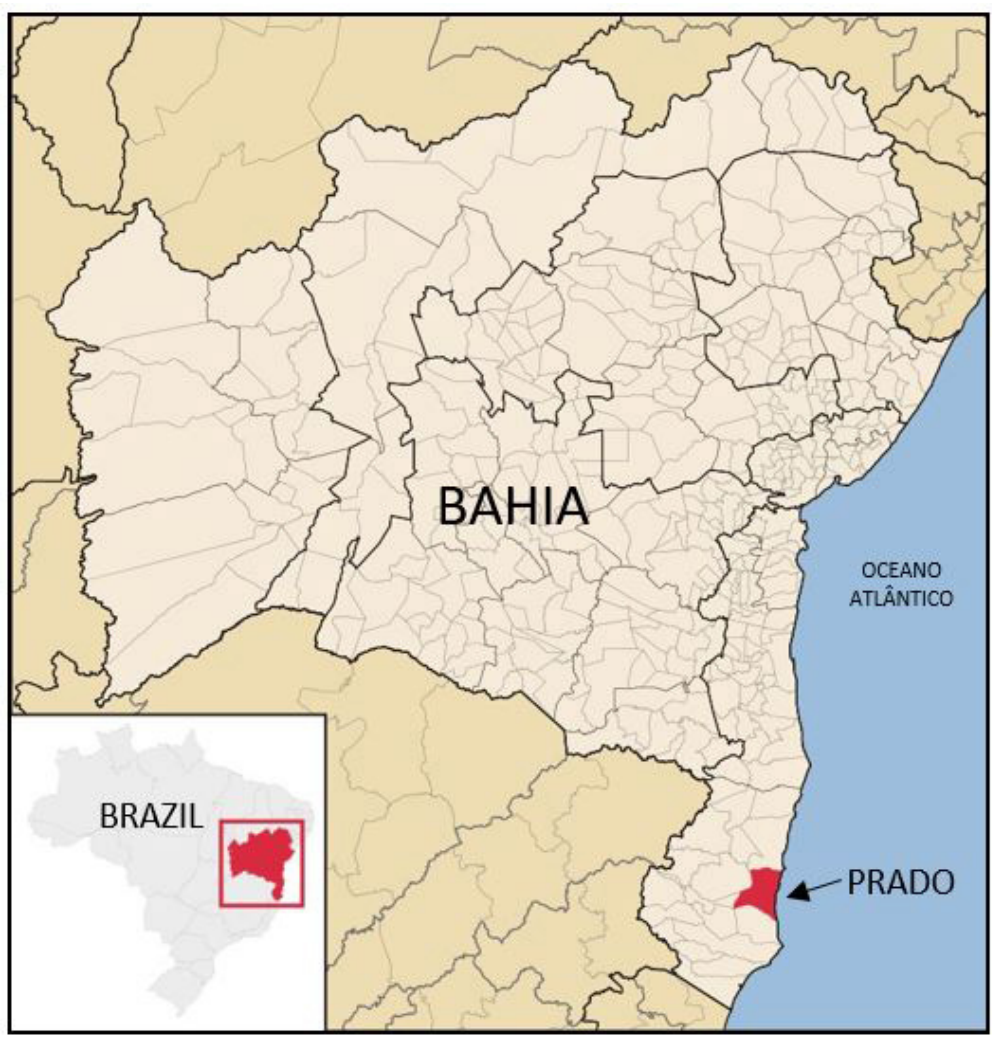

Fonte: Wikipedia / Adaptado pelas autoras.

O litoral brasileiro tem sofrido fortes pressões em virtude da ocupação inadequada e da utilização de seus recursos naturais. Como descrevem Andrade e Dominguez (2002, p. 11):

"Localizada no extremo sul da Bahia, a região costeira entre as cidades de Prado e Mucuri, aparece como uma área de grande potencial turístico, a qual vem sendo alvo de especulação imobiliária, projetos industriais (fábrica de celulose), atividades agropecuárias, exploração de combustíveis fósseis, entre outros. Abrange uma área de $5.104 \mathrm{~km} 2$ e um trecho de cerca de $100 \mathrm{~km}$ do litoral baiano (...). Nesta região estão presentes ecossistemas extremamente frágeis como manguezais, brejos, restingas, dentre outros. Na faixa marinha adjacente, entre 20 e $70 \mathrm{~km}$ da linha de 
Ana Mesquita-Emlinger, Rita de Cássia-Bruno. 'Juntando a fome com a vontade de comer': discussão sobre implementação de infraestrutura cicloviária como forma de promover inclusão social e sustentabilidade em Prado, Bahia, Brasil

costa, está localizado o complexo recifal dos Abrolhos, o maior do Oceano Atlântico Sul Ocidental."

Em 2015, conforme dados do Censo Demográfico Brasileiro, o salário médio mensal em Prado era de 1.8 salários mínimos. A proporção de pessoas ocupadas em relação à população total era de $9.7 \%$. Considerando domicílios com rendimentos mensais de até meio salário mínimo por pessoa, tinha 45.4\% da população nessas condições - posição 2099 de 5570 dentre as cidades do Brasil.

Em 2015, os alunos dos anos inicias da rede pública da cidade tiveram nota média de 4 no IDEB - Índice de Desenvolvimento da Educação Básica. Para os alunos dos anos finais, essa nota foi ainda menor: 3.6. A taxa de mortalidade infantil média na cidade é alarmante: 39.31 para 1.000 nascidos vivos. Quando comparado a cidades do Brasil todo, fica na posição 215 de 5570 .

Prado apresenta apenas $14 \%$ de domicílios com esgotamento sanitário adequado, 43.9\% de domicílios urbanos em vias públicas com arborização e $11.8 \%$ de domicílios urbanos em vias públicas com urbanização adequada (presença de bueiro, calçada, pavimentação e meio-fio). Quando comparado a outras cidades do Brasil, sua posição é 4052 de 5570, 4363 de 5570 e 2601 de 5570, respectivamente.

De acordo com o Atlas Brasil (2013), o Índice de Desenvolvimento Humano (IDHM) em Prado foi de 0,621 em 2010, o que surpreendentemente situa esse município na faixa de Desenvolvimento Humano Médio (IDHM entre 0,600 e 0,699). A dimensão que mais contribuiu para o IDHM do município foi Longevidade, com índice de 0,784, seguida de Renda, com índice de 0,616, e de Educação, com índice de 0,497.

\section{Resultados Preliminares}

As informações apresentadas nesta pesquisa foram coletadas de forma qualitativa e quantitativa, por meio de observação local, estudos bibliográficos, documentação fotográfica e pesquisa com moradores através de questionário com respostas de múltipla escolha.

Os resultados dos questionários mostraram que os respondentes vem de todos os lados da cidade (Gráfico 1). Agrupados por classe econômica, observamos que $64 \%$ deles moram em bairros de baixa renda, $23 \%$ em classe média-baixa, e $13 \%$ deles residem em bairros de classe média-alta. 
Ana Mesquita-Emlinger, Rita de Cássia-Bruno. 'Juntando a fome com a vontade de comer': discussion

on the implementation of cycle infrastructure as a way to promote social equity and sustainability in Prado, Bahia, Brazil

Gráfico 1. Onde você mora em Prado?

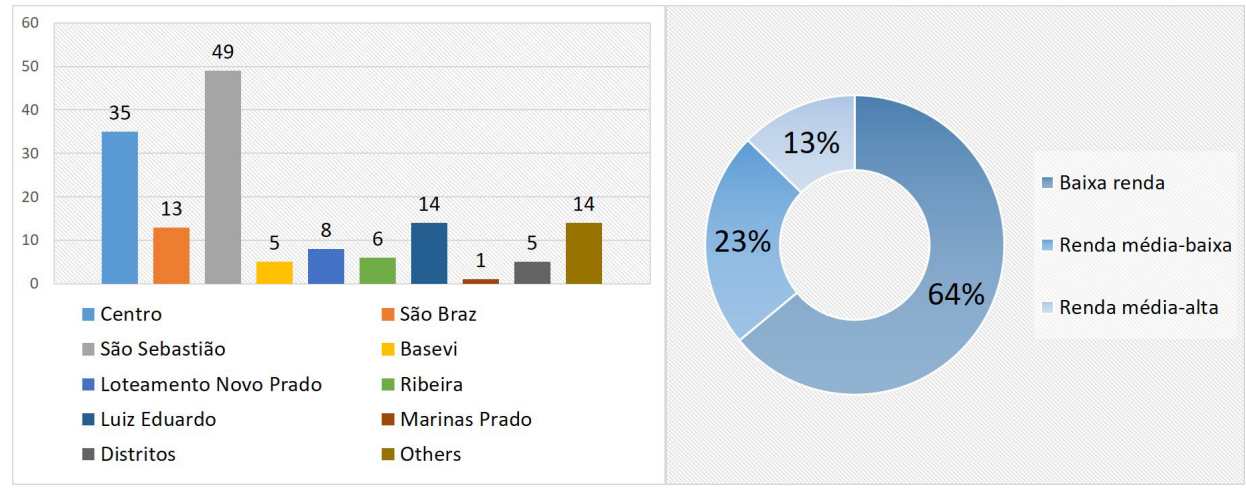

Fonte: Elaborado pelas autoras (2018).

Grande parte dos participantes (57\%) está desempregada (Gráfico 2) e, entre os empregados, $70 \%$ recebe até 2 salários míninos (Gráfico 3). O salário mínimo atual no país é de $\$ 954$. Com base no valor da cesta básica, o Dieese (Departamento Intersindical de Estatística e Estudos Socioeconômicos) calculou em R \$ 3.706,44 o salário mínimo para as despesas básicas de um trabalhador e sua família - quase quatro vezes mais do que ganha a maioria dos participantes da pesquisa.

Gráfico 2. Atualmente você está empregado?

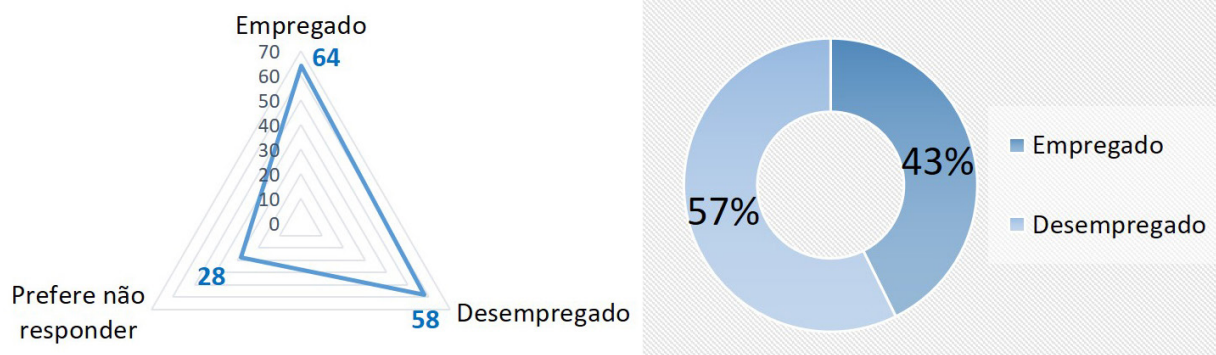

Fonte: Elaborado pelas autoras (2018). 
Ana Mesquita-Emlinger, Rita de Cássia-Bruno. 'Juntando a fome com a vontade de comer': discussão sobre implementação de infraestrutura cicloviária como forma de promover inclusão social e sustentabilidade em Prado, Bahia, Brasil

\section{Gráfico 3. Qual é a sua renda mensal?}
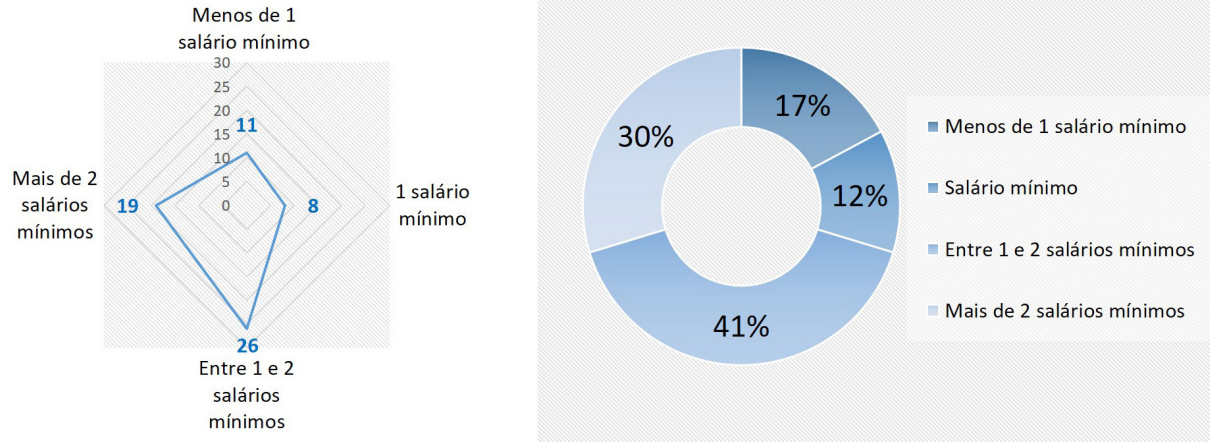

Fonte: Elaborado pelas autoras (2018).

Os resultados mostraram que os moradores usam suas bicicletas durante todos os períodos do dia (Gráfico 4).

Gráfico 4. Que horas você usa a sua bicicleta?

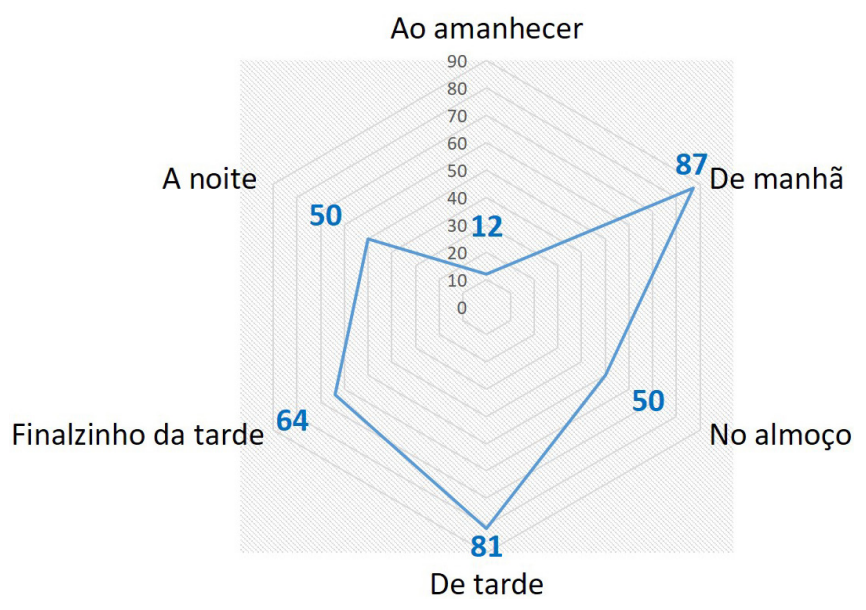

Fonte: Elaborado pelas autoras (2018).

A frequência de uso da bicicleta mostrou-se intensa: $68 \%$ deles usam suas bicicletas mais de quatro vezes na semana, $27 \%$ a usam de duas a três vezes por semana e apenas 5\% a usam uma vez na semana ou menos (Gráfico 5). 
Ana Mesquita-Emlinger, Rita de Cássia-Bruno. 'Juntando a fome com a vontade de comer': discussion on the implementation of cycle infrastructure as a way to promote social equity and sustainability in Prado, Bahia, Brazil

Gráfico 5. Com que frequência você usa a sua bicicleta?

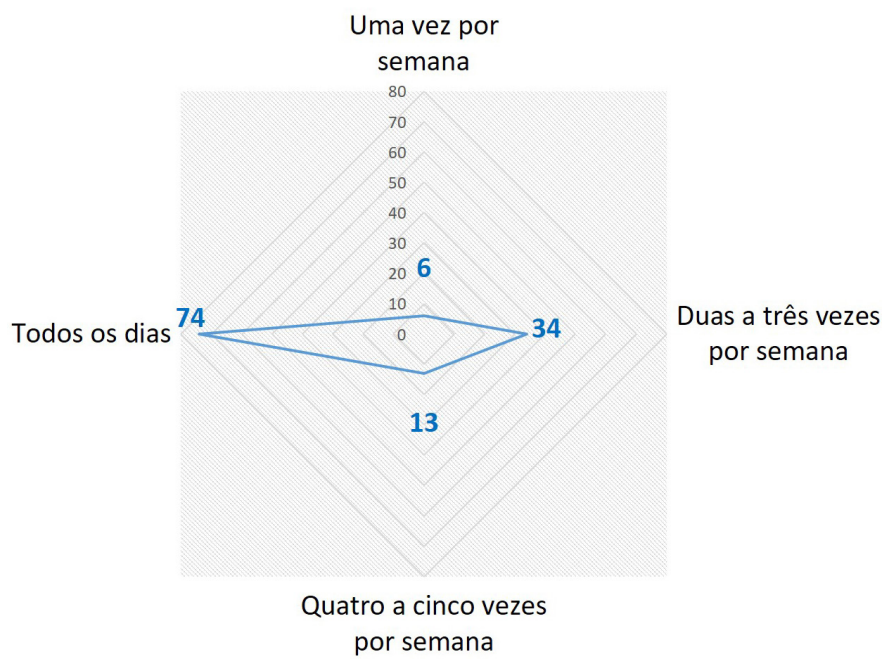

Fonte: Elaborado pelas autoras (2018).

Três são as principais razões pelas quais as pessoas pedalam em Prado: $65 \%$ para transporte, $24 \%$ para lazer, e $11 \%$ para praticar exercício ou esportes (Gráfico 6).

Gráfico 6. Quais são seus principais objetivos ao andar de bicicleta?

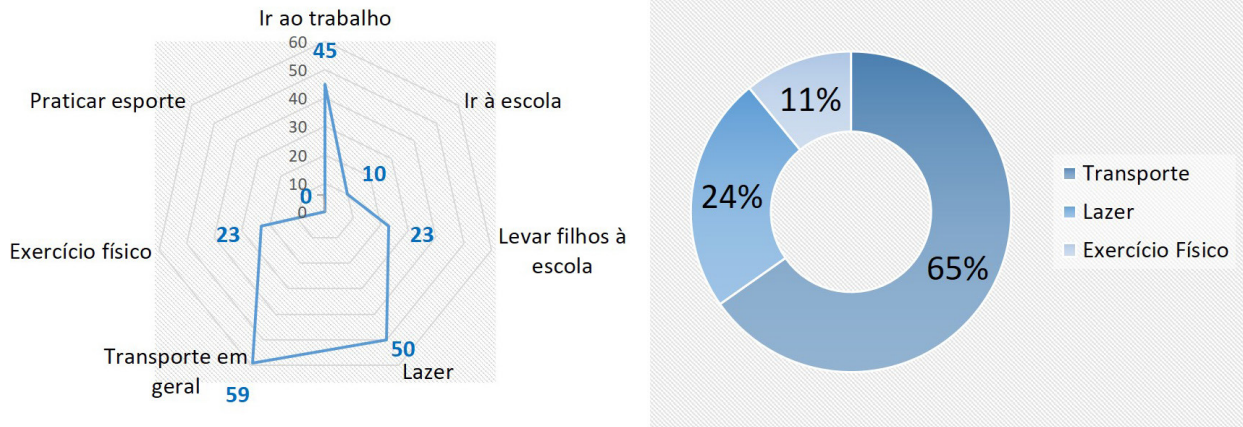

Fonte: Elaborado pelas autoras (2018).

A pesquisa também mostrou que todos os participantes já sofreram algum tipo de abuso enquanto pedalando sua bicicleta em Prado (Gráfico 7). Os abusos mais frequentes foram abuso/ assédio sexual, agressão verbal e agressão física. 
Ana Mesquita-Emlinger, Rita de Cássia-Bruno. 'Juntando a fome com a vontade de comer': discussão sobre implementação de infraestrutura cicloviária como forma de promover inclusão social e sustentabilidade em Prado, Bahia, Brasil

Gráfico 7. Você já foi vítima de algum tipo de abuso enquanto pedalava sua bicicleta?

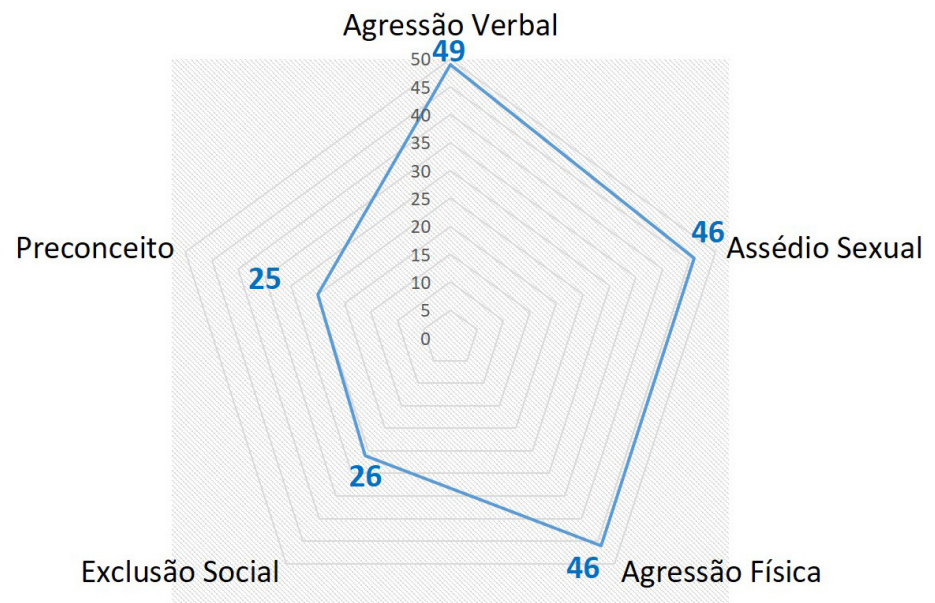

Fonte: Elaborado pelas autoras (2018).

Quando perguntados para expressar sua opinião sobre usar bicicleta em Prado, a grande maioria afirmou que não é seguro e que falta infraestrutura cicloviária nas ruas (Gráfico 8).

Gráfico 8. Qual a sua opinião sobre andar de bicicleta em Prado?

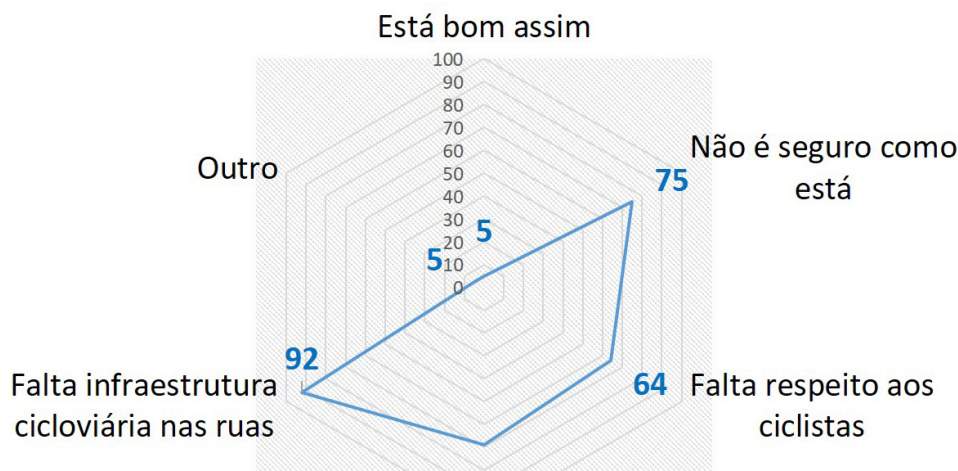

69

Falta estacionamento

seguro para bicicletas

Fonte: Elaborado pelas autoras (2018). 
Aqueles que não usam bicicleta em Prado foram também convidados a participar da pesquisa. Para estes, a principal pergunta era: Por que voce não pedala em Prado? As duas respostas mais frequentes foram: porque eu não tenho bicicleta e porque nos não temos ruas seguras na cidade (Gráfico 9).

Gráfico 9. Por que você não anda de bicicleta em Prado?

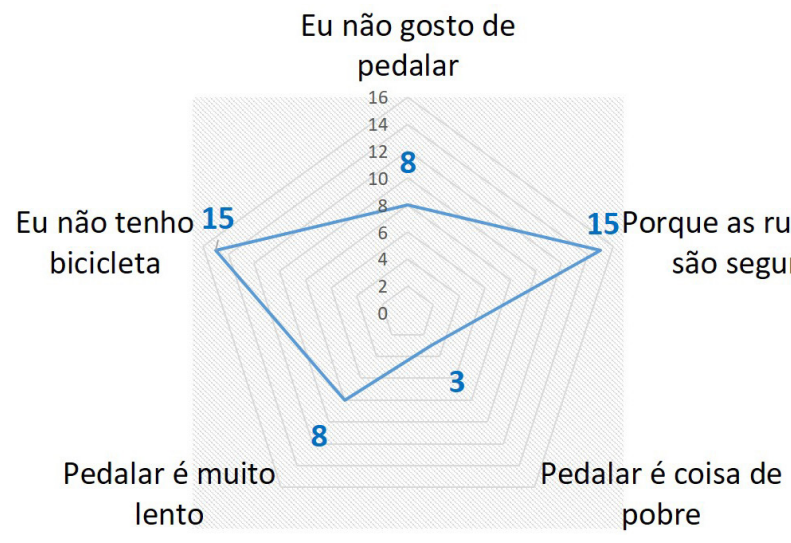

Fonte: Elaborado pelas autoras (2018).

Esses resultados preliminares do estudo cobriram apenas uma pequena parcela da população. Embora esses dados possam ser considerados como indicativos nesta fase inicial, certamente não são representativos dos discursos de todos os segmentos presentes na cidade. Um próximo passo de coleta de dados explorará entrevistas aprofundadas com o poder público local e regional e também com o comércio local e a prestação de serviços. Devido ao turismo que se faz intenso duas vezes ao ano na cidade, a voz dos donos de pousadas será imprescindível nesta nova fase. Um aprofundamento e compreensão das relações entre Estado e sociedade e os canais para abordagens ascendentes e um olhar em alternativas de reforma da política ambiental também fazem parte da próxima agenda de trabalho.

\section{Considerações Finais}

Intervenções urbanas específicas para bicicletas serão cruciais para transformar os padrões de ciclismo na cidade de Prado. Melhorar nossa compreensão dos comportamentos do ciclismo em áreas urbanas, conforme argumentam Fu \& Farber (2017), é um passo importante na produção 
Ana Mesquita-Emlinger, Rita de Cássia-Bruno. 'Juntando a fome com a vontade de comer': discussão sobre implementação de infraestrutura cicloviária como forma de promover inclusão social e sustentabilidade em Prado, Bahia, Brasil

de um sistema de transporte mais sustentável e justo. Cabe à Geografia incorporar as discussões que se referem à mobilidade inclusiva e sustentável da circulação de pessoas, bens e informações, e suas respectivas interações que se dão no território, argumentam Silva e Ferreria, 2016.

Como reflete Soares (2015), é necessário desmistificar a bicicleta como veículo inferior e observar a urgência de implementação de ações e políticas públicas no sentido de prover as cidades brasileiras de infraestrutura que forneça mobilidade e segurança aos ciclistas. No entanto, enquanto o uso do carro continuar supervalorizado no Brasil e a política de transporte continuar dominada pelos modos motorizados, as bicicletas continuarão a ser relegadas a segundo plano na mobilidade urbana. Aqueles que podem adquirir e manter um veículo motorizado continuarão a considerar a bicicleta como uma opção de recreação para seus finais de semana e não para viagens urbanas diárias.

Prado é uma cidade profundamente impactada por problemas sociais e econômicos. Os benefícios econômicos de ciclovias, estacionamento de bicicletas e outras instalações de suporte tendem a ser enormes para as empresas adjacentes. Pesquisas mostram que empresas têm um maior retorno sobre o investimento quando abandonam o estacionamento de carros e priorizam bicicletas. Importante, como ressaltam Torres-Paniagua e Hernández-Vega (2017), para conseguir um aumento na quantidade de viagens de bicicleta, focar em um pacote abrangente de intervenções em infraestrutura, complementado com medidas que vão desde a construção de estacionamento para bicicletas até campanhas educacionais para ciclistas e motoristas.

Este estudo aponta, em última instância, para a imprescindibilidade de olhar a cidade de Prado como uma oportunidade de endereçar problemas de segurança e bem estar dos moradores, bem como questões de sustentabilidade e inclusão social. Investimentos em transporte cicloviário estão completamente alinhados com políticas de redução de emissões de GEE e preocupações com qualidade de ar para um ambiente urbano mais saudável. Parcerias próativas entre agências de trânsito, municípios locais e organizações de defesa de bicicletas, conforme ressaltam Cervero, Caldwell and Cuellar (2013), são fundamentais para garantir que tais melhorias sejam feitas.

Esta pesquisa está também interessada em questionar a idéia, comum na cidade de Prado, e no país em geral, de que bicicleta é meio de transporte para uma fatia marginalizada da população. 
Ana Mesquita-Emlinger, Rita de Cássia-Bruno. 'Juntando a fome com a vontade de comer': discussion on the implementation of cycle infrastructure as a way to promote social equity and sustainability in

O uso de bicicleta, conforme reflete Bantel (2005), pode (e deve) ser visto como um recurso democrático na provisão de transporte urbano para toda a população. No caso de Prado, como em muitas cidades ao redor do mundo, pode-se acrescentar que a provisão de infraestrutura cicloviária, além de endereçar questões ambientais prementes, funciona como meio favorável para integração social, conferindo direitos de cidadania para os ciclistas e pedestres residentes na cidade.

\section{Referências}

Andrade, A. C. da S. e Dominguez, J. M. L. (2002). Informações Geológico-Geomorfológicas Como Subsídios À Análise Ambiental: $\mathrm{O}$ Exemplo Da Planície Costeira De Caravelas - Bahia. Boletim Paranaense de Geociências, n. 51, p. 9-17, 2002. Editora UFPR

Associação Nacional de Transportes Públicos - ANTP, disponível em http://www.antp.org.br/

Atlas Brasil, disponível em http://www.atlasbrasil.org.br/2013/pt/perfil_m/ prado_ba

BANTEL, G. (2005) Bicicleta, Veículo não motorizado (VNM), Revista de Transportes Públicos - ANTP. Ano 27, $2^{\circ}$ Trimestre, São Paulo. p. 59-68.

Barbosa, V. (2016). As capitais com mais ciclovias (e por que não comemorar). In Revista Exame, publicado em 9 jan 2014, 16h31 e revisado em 3 set 2016, 15h40. Disponível em: https://exame.abril.com. br/brasil/as-capitais-com-mais-ciclovias-e-por-que-nao-comemorar/ Caldeira, J. P. (2015). Implantação de ciclovias aumenta número de ciclistas em SP.EmJornaldeTodos os Brasis, disponível em:https:/jornalggn.com.br/ noticia/implantacao-de-ciclovias-aumenta-numero-de-ciclistas-em-sp.

Cervero, R., Caldwell, B. and Cuellar, J. (2013). Bike-and-Ride: Build It and They Will Come. Journal of Public Transportation, 16 (4): 83-105.

Departamento Intersindical de Estatística e Estudos Socioeconomicos Dieese, disponível em: https://www.dieese.org.br/

Fu, L., \& Farber, S. (n.d). Bicycling frequency: A study of preferences and travel behavior in Salt Lake City, Utah. Transportation Research Part A - Policy and Practice, 10130-50. 
Ana Mesquita-Emlinger, Rita de Cássia-Bruno. 'Juntando a fome com a vontade de comer': discussão sobre implementação de infraestrutura cicloviária como forma de promover inclusão social e sustentabilidade em Prado, Bahia, Brasil

Goodyear, S. (2015). The Steady Rise of Bike Ridership in New York. Citylab, disponível em: https://www.citylab.com/transportation/2015/04/ the-steady-rise-of-bike-ridership-in-new-york/390717/

Huang, C. (2015). An Exploratory Scenario for San Francisco to Become A Walking, Bicycling and Transit City.

Programa das Nações Unidas para os Assentamentos Humanos (ONU-Habitat). Disponível em https://nacoesunidas.org/agencia/onuhabitat/

Pucher, J., Komanoff, C., and Schimek, P. (1999). Bicycling renaissance in North America? Recent trends and alternative policies to promote bicycling. Transportation Research, vol. 33, pp. 625-654.

Scott, B., Amel, E., Koger, S., Manning, C. (2016). Psychology for Sustainability, 4th Ed. Routledge

Shrestha, K. K., Ojha, H. R., McManus, P., Rubbo, A., \& Dhote, K. K. (2015) Inclusive Urbanization - Rethinking Policy, Practice and Research in the Age of Climate Change. 1st Edition, Routledge.

Silva, F. O. e Ferreira, W. R. (2016). Logística Urbana E Planejamento Territorial: Uma Abordagem Política. Revista Geográfica de América Central, No 56 pp. $39-55$.

Soares, R. D. G. (2015). Bicicleta e mobilidade urbana - Modismo ou solução sustentável para o transporte na cidade de São Paulo. TCC, USP, SP.

Torres-Paniagua, M. e Hernández-Vega, H. (2017). Estudio De La Movilidad Ciclista En Un Sector De Los Cantones Cartago Y El Guarco, De La Provincia Cartago, Costa Rica. Revista Geográfica de América Central, No 58 pp. 223-251

Walker, B. (2014). Foreword. In Pearson, L., Newton, P. and Roberts, P., Resilient Sustainable Cities, A Future (p. xi). New York: Routledge. Winters, M., Davidson, G., Kao, D., \& Teschke, K. (2011). Motivators and deterrents of bicycling: Comparing influences on decisions to ride. Transportation, 38(1), 153-168. 
